\title{
Magnetic resonance imaging in Alzheimer's disease and mild cognitive impairment
}

\author{
Avinash Chandra ${ }^{1}$ [D $\cdot$ George Dervenoulas ${ }^{1} \cdot$ Marios Politis $^{1} \cdot$ for the Alzheimer's Disease Neuroimaging Initiative
}

Received: 6 July 2018 / Revised: 7 August 2018 / Accepted: 11 August 2018 / Published online: 17 August 2018

(c) The Author(s) 2018

\begin{abstract}
Research utilizing magnetic resonance imaging (MRI) has been crucial to the understanding of the neuropathological mechanisms behind and clinical identification of Alzheimer's disease (AD) and mild cognitive impairment (MCI). MRI modalities show patterns of brain damage that discriminate AD from other brain illnesses and brain abnormalities that are associated with risk of conversion to $\mathrm{AD}$ from $\mathrm{MCI}$ and other behavioural outcomes. This review discusses the application of various MRI techniques to and their clinical usefulness in AD and MCI. MRI modalities covered include structural MRI, diffusion tensor imaging (DTI), arterial spin labelling (ASL), magnetic resonance spectroscopy (MRS), and functional MRI (fMRI). There is much evidence supporting the validity of MRI as a biomarker for these disorders; however, only traditional structural imaging is currently recommended for routine use in clinical settings. Future research is needed to warrant the inclusion for more advanced MRI methodology in forthcoming revisions to diagnostic criteria for AD and MCI.
\end{abstract}

Keywords Magnetic resonance imaging $\cdot$ Neuropathology $\cdot$ Alzheimer's disease $\cdot$ Mild cognitive impairment

\section{Introduction}

Alzheimer's disease (AD) is a neurodegenerative disorder and the most common cause of dementia. Mild cognitive impairment (MCI) is the prodromal form of $\mathrm{AD}$ and is characterized by neurocognitive dysfunction, but not to the

Data used in preparation of this article were obtained from the Alzheimer's Disease Neuroimaging Initiative (ADNI) database (adni.loni.usc.edu). As such, the investigators within the ADNI contributed to the design and implementation of ADNI and/or provided data but did not participate in analysis or writing of this report. A complete listing of ADNI investigators can be found at: http://adni.loni.usc.edu/wp-content/uploads/how_to_apply/ADNI_ Acknowledgement_List.pdf.

Marios Politis

marios.politis@kcl.ac.uk

Avinash Chandra

avinash.chandra@kcl.ac.uk

George Dervenoulas

george.dervenoulas@kcl.ac.uk

1 Neurodegeneration Imaging Group (NIG), Maurice Wohl Clinical Neuroscience Institute, Institute of Psychiatry, Psychology and Neuroscience (IoPPN), King's College London, 125 Coldharbour Lane, Camberwell, London SE5 9NU, UK extent of dementia, and minor difficulties in functional ability. The neuropathological hallmarks of AD include neurofibrillary tangles (NFTs) and beta-amyloid (A $\beta$ ) neuritic plaques. The AD brain contains increased levels of hyperphosphorylated tau. In this state, the main functions of normal tau are disrupted and the polymerization of paired helical filaments or NFTs, which are correlated with synaptic loss, occurs. Overproduction of amyloid precursor protein is also characteristic in $\mathrm{AD}$, which results in elevated levels of $A \beta_{42}$ and neuritic plaque formation. This exerts oxidative and inflammatory stress, which contributes to neuronal damage [1].

Through the in vivo visualization of neuropathology, magnetic resonance imaging (MRI) research has been paramount in the clinical identification of MCI and AD. Diagnostic criteria recommend the consideration of abnormalities on structural MRI [2,3]. More advanced MR techniques include diffusion tensor imaging (DTI), arterial spin labelling (ASL), magnetic resonance spectroscopy (MRS), and functional magnetic resonance imaging (fMRI), which have not yet been established for routine clinical use. The aim of this review will be to provide an overview of the application of the various MR modalities in $\mathrm{AD}$ and MCI. Another clinically useful neuroimaging technology is positron emission 
tomography (PET) [4]; however, this is beyond the scope of the current work.

\section{Structural imaging}

Structural imaging modalities reveal brain atrophy and other static tissue abnormalities (Table 1; Fig. 1). Progression of atrophy follows Braak staging [5] and is first observed in medial temporal lobe (MTL) structures, including the entorhinal cortex (ERC) and hippocampus [6, 7]. Compared to controls, hippocampal volumes for $\mathrm{AD}$ patients are reduced by $26-27 \%$ and ERC volumes by $38-40 \%$ [6]. MCI patients show intermediate levels of MTL atrophy [7]. The presence of diffuse hippocampal atrophy is related to deficits in executive functioning and memory for AD patients [8]. As the disease progresses, atrophy advances to the remainder of the MTL where grey matter (GM) loss occurs in the medial temporal gyrus, parahippocampus, parahippocampal and fusiform gyri, and temporal pole [9]. Nesteruk and colleagues [10] found that MTL atrophy discriminates those who will convert from MCI to AD from non-converters. It also differentiates AD from dementia with Lewy bodies (DLB) and Parkinson's disease with dementia (PDD), where AD patients show the greatest reductions in hippocampal volume $[11,12]$.

Table 1 Research studies examining region-specific patterns of neuropathology in AD and MCI using structural MRI

\begin{tabular}{|c|c|c|c|}
\hline Study & Imaging modality & Sample & Main findings \\
\hline Du et al. [6] & Structural MRI & $20 \mathrm{AD}, 25$ cognitively normal (CN) & $\begin{array}{l}\text { AD patients demonstrated GM loss in the } \\
\text { hippocampus and ERC, with a higher atro- } \\
\text { phy rate in the ERC }\end{array}$ \\
\hline Pennanen et al. [7] & Structural MRI & $48 \mathrm{AD}, 65 \mathrm{MCI}, 59$ controls & $\begin{array}{l}\text { Hippocampal and ERC atrophies were found } \\
\text { in AD and MCI patients, with MCI patients } \\
\text { showing intermediate levels }\end{array}$ \\
\hline Li et al. [9] & Structural MRI & $64 \mathrm{AD}, 72$ controls ( 14 with $\mathrm{AD}$ on follow-up) & $\begin{array}{l}\text { Early in the course of AD, the ERC and hip- } \\
\text { pocampus are the primary sites of atrophy. } \\
\text { In later stages, other MTL brain structures } \\
\text { are affected }\end{array}$ \\
\hline Cavedo et al. [13] & Structural MRI & $19 \mathrm{AD}, 19$ controls & $\begin{array}{l}\text { GM reductions were demonstrated in the } \\
\text { amygdala for } \mathrm{AD} \text { patients }\end{array}$ \\
\hline Thomann et al. [14] & Structural MRI & 21 early $\mathrm{AD}, 21$ controls & $\begin{array}{l}\text { Atrophy of the olfactory bulb tract was found } \\
\text { for AD patients }\end{array}$ \\
\hline Guo et al. [15] & Structural MRI & $13 \mathrm{AD}, 14$ controls & $\begin{array}{l}\text { GM reductions in parahippocampal gyrus, } \\
\text { middle and superior temporal gyrus, insula, } \\
\text { parietal lobule, thalamus, hippocampus, and } \\
\text { cingulate gyrus were demonstrated for AD } \\
\text { patients }\end{array}$ \\
\hline De Jong et al. [16] & Structural MRI & $\begin{array}{l}69 \text { probable } \mathrm{AD}, 70 \text { subjects with memory } \\
\text { complaints }\end{array}$ & $\begin{array}{l}\text { Compared to subjects with memory com- } \\
\text { plaints, GM loss was shown in the putamen } \\
\text { and thalamus for AD patients }\end{array}$ \\
\hline Kilimann et al. [19] & Structural MRI & $134 \mathrm{AD}, 41 \mathrm{MCI}, 148$ controls & $\begin{array}{l}\text { Volumetric reductions in brain areas within } \\
\text { the basal forebrain cholinergic system were } \\
\text { displayed for AD and MCI patients }\end{array}$ \\
\hline Duarte et al. [20] & Structural MRI & 14 probable $\mathrm{AD}, 32 \mathrm{MCI}, 14$ controls & $\begin{array}{l}\text { Frontal, parietal and temporal lobe atrophies } \\
\text { were found for AD patients and frontal and } \\
\text { temporal GM losses were present for MCI } \\
\text { patients }\end{array}$ \\
\hline Vasavada et al. [22] & Structural MRI & $15 \mathrm{AD}, 21 \mathrm{MCI}, 27 \mathrm{CN}$ & $\begin{array}{l}\text { Brain atrophy was displayed in the hippocam- } \\
\text { pus and the primary olfactory cortex for AD } \\
\text { and MCI patients }\end{array}$ \\
\hline Tabatabaei-Jafari et al. [23] & Structural MRI & $191 \mathrm{AD}, 398 \mathrm{MCI}, 229 \mathrm{CN}$ & $\begin{array}{l}\text { GM reductions in the cerebellum were found } \\
\text { for } \mathrm{AD} \text { patients }\end{array}$ \\
\hline Lee et al. [24] & Structural MRI & $50 \mathrm{AD}, 50$ controls & $\begin{array}{l}\text { Volumetric reductions in the brainstem were } \\
\text { displayed in AD patients }\end{array}$ \\
\hline Capizzano et al. [27] & Structural MRI & 81 probable AD, 19 controls & $\begin{array}{l}\text { A high degree of WMHs was found in } \mathrm{AD} \\
\text { patients: } 70 \% \text { in the frontal lobe, } 22 \% \text { in the } \\
\text { parietal lobe, } 3.5 \% \text { in the temporal lobe, and } \\
1 \% \text { in the occipital lobe }\end{array}$ \\
\hline
\end{tabular}




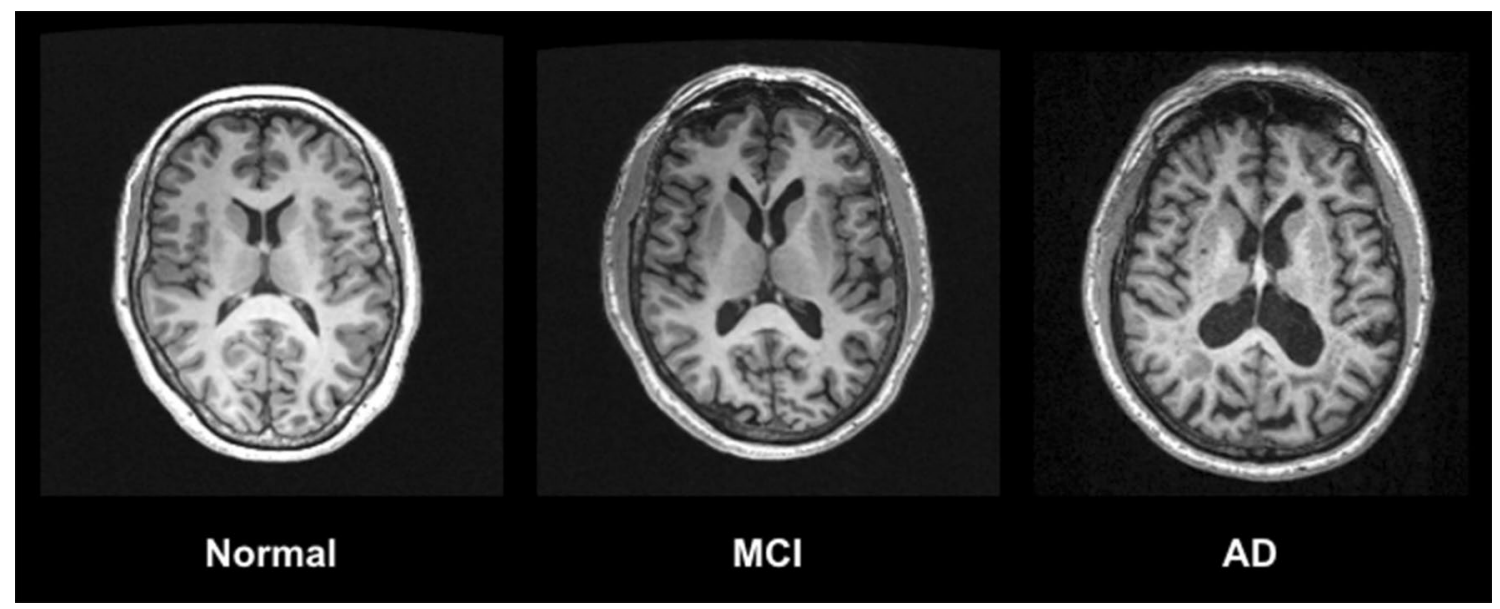

Fig. 1 T1-weighted MRI imaging using an MPRAGE (Magnetisation Prepared Rapid Gradient Echo) sequence shows decreased GM volume in an $\mathrm{AD}$ patient compared to a healthy control and intermediate GM decline in a patient with MCI

Additional limbic structures including the amygdala, olfactory bulb tract, cingulate gyrus, and thalamus are impacted in AD [13-16]. GM loss in these regions is associated with cognitive dysfunction and neuropsychiatric symptomatology $[17,18]$. As the disease progresses, atrophy spreads to cortical regions. Frontal, parietal, and temporal brain areas experience volumetric reductions, and so do the putamen and basal forebrain cholinergic system [15, 16, 19, 20]. Cholinergic abnormalities in AD have been further highlighted through the use of molecular imaging technologies [21]. Atrophy is also found in the primary olfactory cortex [22], in addition to lower-level brain areas including the cerebellum and brainstem [23, 24]. MCI is notable for frontal and temporal GM loss, and atrophy in the primary olfactory cortex and some basal forebrain cholinergic system structures [19, 20, 22]. No volumetric differences were found between AD patients with and without hypertension [25].

Structural MRI scans can also display white matter hyperintensities (WMHs), which indicate demyelination and axonal loss [26] (Table 1; Fig. 2). Compared to controls, patients with AD demonstrate greater WMHs with the majority in frontal lobe [27]. For patients along the AD spectrum, WMHs correlate with hippocampal atrophy [28], in addition to neuropsychological impairment and psychiatric disturbances [29, 30]. Considering differential diagnoses, patients with vascular dementia (VaD) have higher volumes of WMHs than in AD [31]. Periventricular WMHs are predictive of progression from MCI to AD, with an increase of one point in WMH rating associated with a $59 \%$ increased risk of phenoconversion [32].

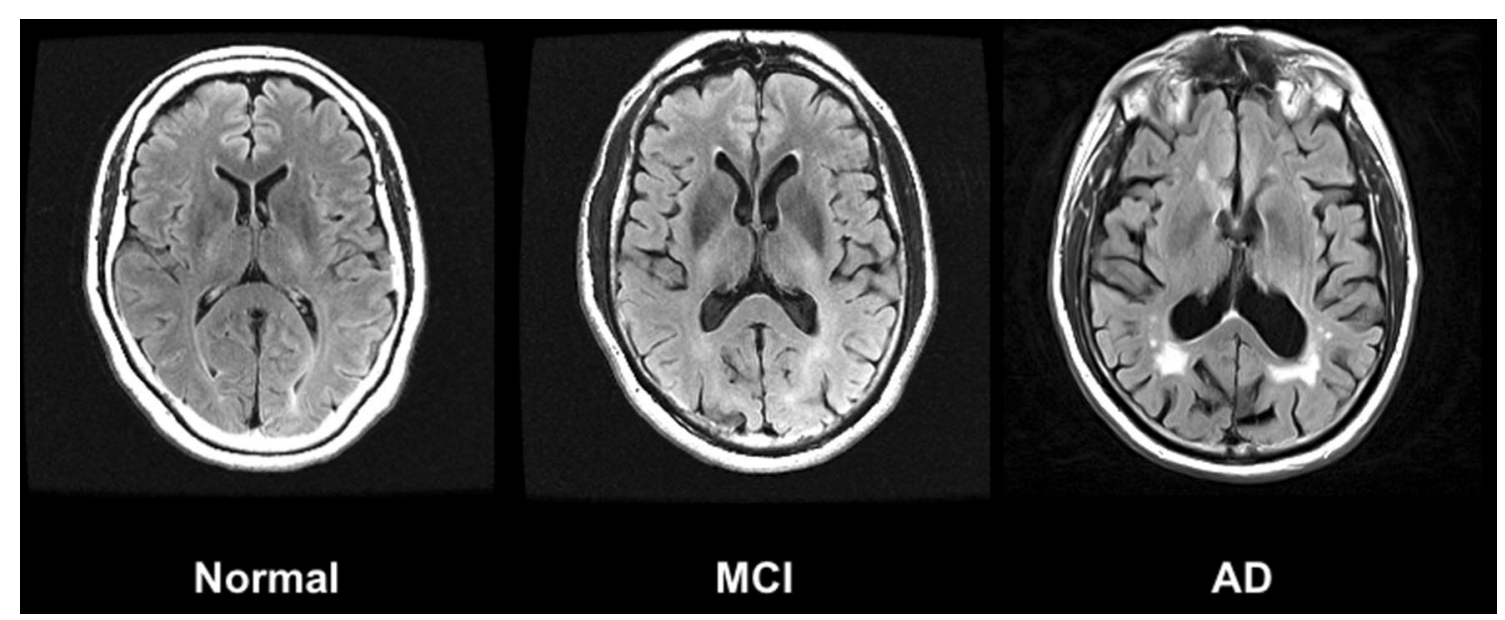

Fig. 2 T2-weighted MRI imaging using a FLAIR (Fluid Attenuated Inversion Recovery) sequence shows increased WMHs in an AD patient compared to a healthy control and intermediate levels of WMHs in a patient with MCI 


\section{Advanced MR techniques}

DTI utilizes the displacement of water molecules to measure white matter tract integrity (Table 2 ). The primary metrics of DTI include mean diffusivity (MD) or the average rate of water molecule diffusivity and fractional anisotropy (FA) or the variability associated with diffusion [33]. In AD, increased MD is noted in frontal, occipital, parietal, and temporal areas including the hippocampus; however, in MCI, these increases are absent in frontal and occipital regions. In AD, decreased FA is localized to the cingulum, corpus callosum, superior lateral fasciculus and uncinate fasciculus and throughout temporal, occipital and frontal white matter. Patients with MCI display a similar pattern, but with no FA irregularities in occipital and parietal areas [34]. MD increases in the basal forebrain are associated with increased risk of progression from MCI to $\mathrm{AD} \mathrm{[35],} \mathrm{and} \mathrm{FA} \mathrm{and} \mathrm{MD} \mathrm{abnormalities} \mathrm{are} \mathrm{associated}$ with memory and executive dysfunction [36, 37]. Diffusivity metrics also discriminate $\mathrm{AD}$ from other dementias where reduced FA is present in frontal areas for frontotemporal dementia (FTD) compared to $\mathrm{AD}$, and increased $\mathrm{MD}$ is present in parietal and temporal regions for $\mathrm{AD}$ in contrast to DLB [38, 39]. However, DTI technology shows particular sensitivity to motion, which could lead to artifacts that might skew results. Comparatively long scanning times could increase the probability of such errors [40], indicating that this technique may not be particularly well suited for practical clinical use.

Changes in the neurovasculature system, namely in cerebral blood flow (CBF), can be detected by MR imaging using ASL (Table 2). Notable hypoperfusion is present in the posterior cingulate, precuneus, and, occipital, temporal, parietal cortical areas in $\mathrm{AD}$ and $\mathrm{MCI}$, and in frontal and orbitofrontal cortex, and the hippocampus in $\mathrm{AD}$. $\mathrm{AD}$ patients demonstrate greater $\mathrm{CBF}$ declines in cortex found in temporal, parietal, frontal, and orbitofrontal areas, in addition to the thalamus and middle temporal structures including the hippocampus and amygdala when compared to those with MCI [41-43]. Limited increases in CBF have been shown in the basal ganglia, amygdala, and hippocampus in MCI, and anterior cingulate in $\mathrm{AD}$, which suggests compensatory mechanisms within the brain for cerebrovascular damage [43]. Regarding disease-related outcomes, regional hypoperfusion is associated with progression from MCI to $\mathrm{AD}$, in addition to cognitive and functional deterioration [44]. Measures of perfusion on ASL also discriminate AD from $\mathrm{VaD}$, DLB, and FTD. Differential patterns of CBF reduction were shown in frontal and temporal areas when comparing $\mathrm{AD}$ to $\mathrm{VaD}$. Whilst demonstrating the highest degree of hypoperfusion throughout the brain, temporal regions are spared in DLB. In comparison, reduced temporal and frontal CBF is characteristic of AD and FTD, respectively [45, 46]. ASL utilizes magnetically labelled blood water as a tracer and individual differences in blood vessel properties could

Table 2 Research studies examining region-specific patterns of neuropathology in AD and MCI using advanced MR modalities

\begin{tabular}{|c|c|c|c|}
\hline Study & $\begin{array}{l}\text { Imaging } \\
\text { modal- } \\
\text { ity }\end{array}$ & Sample & Main findings \\
\hline Sexton et al. [34] & DTI & Meta-analysis of 41 studies & $\begin{array}{l}\text { MD increases were found globally in WM in AD and in temporal and } \\
\text { parietal WM in MCI. FA decreases were found in temporal, occipital and } \\
\text { frontal WM in AD and frontal and temporal WM in MCI }\end{array}$ \\
\hline Alexopoulos et al. [41] & ASL & $19 \mathrm{AD}, 24 \mathrm{MCI}, 24$ controls & $\begin{array}{l}\text { Hypoperfusion was noted in parietal, temporal, and occipital cortex, and the } \\
\text { precuneus in MCI and AD patients }\end{array}$ \\
\hline Mak et al. [42] & ASL & $13 \mathrm{AD}, 15$ controls & $\begin{array}{l}\text { Reductions in } \mathrm{CBF} \text { were found in the hippocampus and posterior cingulate } \\
\text { for patients with } \mathrm{AD}\end{array}$ \\
\hline Dai et al. [43] & ASL & $37 \mathrm{AD}, 29 \mathrm{MCI}, 38$ controls & $\begin{array}{l}\text { In } \mathrm{MCI} \text {, decreases in } \mathrm{CBF} \text { were found in the posterior cingulate and precu- } \\
\text { neus and increases in } \mathrm{CBF} \text { were found in the hippocampus, basal ganglia, } \\
\text { and amygdala. In } \mathrm{AD} \text { decreases in } \mathrm{CBF} \text { were found in frontal, parietal, } \\
\text { temporal, orbitofrontal cortex, and the precuneus and increases in CBF } \\
\text { were found in the anterior cingulate gyrus. Compared to MCI patients, AD } \\
\text { patients showed decreased CBF in temporal, parietal, frontal orbitofrontal } \\
\text { cortex and temporal regions such as hippocampus, amygdala, and thala- } \\
\text { mus }\end{array}$ \\
\hline Zhu et al. [49] & MRS & $14 \mathrm{AD}, 22 \mathrm{CN}$ elderly subjects & $\begin{array}{l}\text { Increased } \mathrm{mI}, \mathrm{mI} / \mathrm{Cr} \text { and decreased NAA and } \mathrm{NAA} / \mathrm{Cr} \text { ratios were found in } \\
\text { parietal areas for patients with } \mathrm{AD} \text {. NAA/mI ratios were the best classifier } \\
\text { for } \mathrm{AD}\end{array}$ \\
\hline Tumati et al. [50] & MRS & Meta-analysis of 29 studies & $\begin{array}{l}\text { In the posterior cingulate, } \mathrm{Cho} / \mathrm{Cr} \text { ratios are increased, and } \mathrm{NAA} / \mathrm{mI} \text { ratios } \\
\text { are decreased for } \mathrm{AD} \text { patients. In the hippocampus, } \mathrm{mI} / \mathrm{Cr} \text { ratios are } \\
\text { increased for } \mathrm{AD} \text { patients }\end{array}$ \\
\hline
\end{tabular}


lead to variable transit times for its delivery. This might result in artificial changes in signal intensity, which a clinician might mistake as a disease-related abnormality in CBF. Another barrier to the employment of ASL in clinical practice is its low signal to noise ratio, which leads to reductions in image quality [47].

MRS assesses brain metabolite levels and its parameters are expressed as concentration or ratios to standardize values [48] (Table 2). When examining region-specific changes in $\mathrm{AD}$, lower $\mathrm{N}$-acetylaspartate (NAA) and NAA/Creatine $(\mathrm{Cr})$ and higher myo-Inositol $(\mathrm{mI})$ and $\mathrm{mI} / \mathrm{Cr}$ ratios are found in parietal regions. Parietal NAA/mI ratios are also deemed a valid discriminator of $\mathrm{AD}$ [49]. In MCI, NAA/mI ratios are lowered and Choline(Cho)/Cr ratios are increased in the posterior cingulate gyrus, whereas $\mathrm{mI} / \mathrm{Cr}$ ratios are increased in the hippocampus [50]. Clinically, decreased NAA markers are predictive of phenoconversion to dementia and cognitive dysfunction [51, 52]. NAA/Cr and NAA/mI ratios discriminate $\mathrm{AD}$ from $\mathrm{VaD}$, and glutamate/Cr ratios differentiate DLB from AD. Metabolic ratios are substantially lower in $\mathrm{AD}$ patients compared to $\mathrm{VaD}$, but higher in widespread brain regions relative to DLB $[53,54]$. Whilst MRS is able to study molecular processes in the brain non-invasively without exposure to ionizing radiation, this technique is limited by its low sensitivity [55]. Resultant attenuated signal strength makes it difficult to recommend its use by clinicians for diagnostic purposes in AD and MCI.

\section{Functional imaging}

Functional MRI generates dynamic representations of brain activity through bold oxygen level-dependent (BOLD) signal, which measures changes in blood flow and volume [56] (Table 3). On memory tasks, patients with AD show no or less activation of hippocampal and other medial temporal structures when compared to controls. Findings of increased brain activity during encoding in parietal and posterior cingulate areas indicate some degree of compensation by the brain in lieu of medial temporal dysfunction $[57,58]$. Patients with MCI have demonstrated similar hippocampal deactivation to those with $\mathrm{AD}$ during recall [59], but with hyperactivation during encoding phases [60,61], which might underline mechanistic compensation in prodromal stages. fMRI findings in AD extend to tasks of working memory, visuospatial ability, attention, semantic knowledge, and motor performance [62-66] and in MCI tasks of attention and working memory $[62,64,67]$.

Resting-state fMRI provides insight into functional connectivity among structures in intrinsic networks implicated in the AD spectrum (Table 3). One particular network of interest is the default mode network (DMN), where increased neural activity is shown at rest compared to task engagement. Brain structures implicated in the DMN include the posterior cingulate cortex (PCC), ventral anterior cingulate cortex, medial prefrontal cortex, inferior parietal cortex, dorsolateral prefrontal cortex, inferolateral temporal cortex, orbitofrontal cortex, and parahippocampal gyrus [68]. Abnormal coactivation at rest in $\mathrm{AD}$ was shown between medial temporal structures such as the hippocampus and entorhinal cortex and the posterior cingulate cortex (PCC) [69]. This evidences the significance of the MTL in the DMN and establishes altered connectivity in the DMN as an indicator for AD. Levels of PCC connectivity to other DMN structures is associated with neuropsychological impairment and declines in PCC-retrosplenial cortex connectivity is associated with lower $A \beta$ levels in the CSF for $\mathrm{AD}$ patients [70].

There is a decrease in posterior and an increase in anterior and ventral DMN regions early in AD. 2-4 years later all regions show marked declines in connectivity [71]. This supports the notion that early mechanistic compensation occurs intrinsically within the DMN, but eventually global neurodegeneration occurs. This pattern of DMN dysfunction has been noted in MCI with limited increases in activation between DMN structures, indicative of prodromal compensatory mechanisms $[72,73]$. Other large-scale brain networks that show disruption in AD include thalamo-cortical, dorsal attention, visual, and sensorimotor ones [74-76]. Whilst fMRI provides unique insight into pathophysiology, its use in the clinical routine is not supported [77]. This is due to primary limitations including a low signal or contrast to noise ratio and the questionable validity of BOLD signal as a measure of neuronal activity. Unexplained variability in this signal might result from hemodynamic factors that are not controlled for [78].

\section{Conclusions}

$\mathrm{AD}$ is a devastating illness that leads to cognitive impairment and functional deterioration. MRI modalities have shown substantial utility in identifying biomarkers for $\mathrm{AD}$ and MCI pathology. These, in turn, can be used to improve diagnostic accuracy and develop novel molecular-based treatment interventions. Whilst only traditional structural modalities are recommended for diagnosis in clinical practice of MCI and AD, there is a need for further research to overcome methodological limitations of more advanced ones, which provide unique insight into disease-specific patterns of neuropathology. This should hopefully warrant their inclusion in diagnostic criteria for $\mathrm{MCI}$ and $\mathrm{AD}$ in the future. 
Table 3 Research studies examining region-specific patterns of neuropathology in AD and MCI using functional MRI

\begin{tabular}{lll}
\hline Study & Imaging modality & Sample \\
\hline Small et al. [57] & Task-based fMRI & $\begin{array}{c}4 \text { AD, } 12 \text { subjects with isolated memory } \\
\text { decline, } 4 \text { controls }\end{array}$ \\
& & \\
Sperling et al. [58] & Task-based fMRI & $\begin{array}{c}7 \text { AD, 10 young control subjects, } 10 \text { elderly } \\
\text { control subjects }\end{array}$ \\
& & \\
Petrella et al. [59] & Task-based fMRI & $\begin{array}{c}13 \text { AD, 34 aMCI, 28 healthy elderly control } \\
\text { subjects }\end{array}$
\end{tabular}

Main findings

Reduced activation in regions of the hippocampus was found during a facial recognition task for AD patients. A similar finding was observed for patients with isolated memory decline

Reduced activation in hippocampal areas and increased activation in the parietal regions and the posterior cingulate were found during an encoding task for AD patients

Decreased activation was found in middle temporal areas and increased activation was shown in posteromedial cortical regions for AD patients during an encoding task. Patients with MCI showed an intermediate but similar profile

Trivedi et al. [60] Task-based fMRI 16 aMCI, 23 controls

Reduced activation was noted in frontal areas and increased activation was present in hippocampal areas for MCI patients during an encoding task. During recognition, this region-specific pattern of activation was reversed

Parra et al. [61] Task-based fMRI 10 AD, 10 MCI, 10 controls

Comparing control subjects and MCI patients, decreased activation was found in the hippocampus and parahippocampus in $\mathrm{AD}$ patients during incidental encoding. Increased activation was found for MCI patients relative to control subjects

Yetkin et al. [62] Task-based fMRI $11 \mathrm{AD}, 10 \mathrm{MCI}, 9$ controls

Thiyagesh et al. [63] Task-based fMRI 12 AD, 13 elderly control subjects

Li et al. [64]

Task-based fMRI

$10 \mathrm{AD}, 9 \mathrm{MCI}, 9$ elderly control subjects

Increased activation in frontal and temporal regions, fusiform gyrus, and anterior cingulate gyrus was displayed for $\mathrm{AD}$ and MCI patients during a working memory task. For selected areas, MCI patients showed greater activation than $\mathrm{AD}$ patients

Declines in activation in parietal, parieto-occipital, and premotor cortical areas and increased activation of additional parietal structures was found in $\mathrm{AD}$ during an observational visuospatial task

Reduced activation was found in prefrontal cortical areas for $\mathrm{AD}$ patients and increased activation in these same regions was found for MCI patients during a Stoop colour-word interference task

McGeown et al. [65] Task-based fMRI 29 AD, 19 controls

No activation in parietal regions and decreased activation in prefrontal areas was found for AD patients during a semantic knowledge task

Vidoni et al. [66] Task-based fMRI 9 AD, 10 controls

Reduced activation was found in the premotor and supplementary motor regions, and the cerebellum, whilst increased activation was evidenced in the primary motor cortices for $\mathrm{AD}$ patients during a motor task

Van Dam et al. [67] Task-based fMRI 8 aMCI, 8 controls

Increased activation was shown in the temperoparietal junction, angular gyrus, and precuneus, whereas attenuated activation was seen in prefrontal regions and the anterior cingulate for aMCI patients during an attentional (executive control, alerting and orienting) task 
Table 3 (continued)

\begin{tabular}{lll}
\hline Study & Imaging modality & Sample \\
\hline Greicius et al. [69] & Resting-State fMRI & 15 AD, 18 controls \\
& & \\
Damoiseaux et al. [71] & Resting-State fMRI & Baseline: 21 AD, 18 controls \\
& & Follow-up: 11 AD, 10 controls
\end{tabular}

Yu et al. [72] Resting-State fMRI $32 \mathrm{AD}, 26 \mathrm{MCI}, 58$ controls

Das et al. [73] Resting-State fMRI 17 aMCI, 31 controls

Zhou et al. [74] Resting-State fMRI 35 AD, 27 MCI, 27 controls

Li et al. [75]

Resting-State fMRI 15 AD, 16 healthy elderly control subjects

Zheng et al. [76] Resting-State fMRI 32 AD, 38 controls

Main findings

Reduced connectivity was shown between medial temporal structures and the posterior cingulate cortex for $\mathrm{AD}$ patients

Compared to control subjects at baseline, declines in connectivity were seen in the posterior DMN and increased activation was found for areas within the ventral and anterior $\mathrm{DMN}$ for $\mathrm{AD}$ patients. Compared to control subjects at follow-up, decreased connectivity between regions within the anterior, ventral, and posterior DMN in addition to sensorimotor network were shown for AD patients. Compared to control subjects, declines in activation over time were greater for $\mathrm{AD}$ patients

Increased connectivity between posterior cingulate and non-DMN regions but declines in activation between the posterior cingulate and areas within the DMN were found for $\mathrm{AD}$ patients. An opposite pattern of connectivity was shown for MCI patients

A greater degree of functional connectivity was shown within regions belonging to the medial temporal lobe, whereas declines in activity were seen between DMN and medial temporal structures for MCI patients

Declines in functional connectivity within a range of regions within the thalamo-cortical network and thalamo-DMN were observed for AD patients. MCI patients showed similar but intermediate deteriorations

Declines in functional connectivity within a range of regions within the dorsal attention network but not the ventral attention network were found for $\mathrm{AD}$ patients

Disturbed functional connectivity was seen in several main networks including the DMN, visual network, and sensorimotor network in AD patients
Acknowledgements Data collection and sharing for this project, specifically generation of figures depicting MR images, was funded by the Alzheimer's Disease Neuroimaging Initiative (ADNI) (National Institutes of Health Grant U01 AG024904) and DOD ADNI (Department of Defense award number W81XWH-12-2-0012). ADNI is funded by the National Institute on Aging, the National Institute of Biomedical Imaging and Bioengineering, and through generous contributions from the following: AbbVie, Alzheimer's Association; Alzheimer's Drug Discovery Foundation; Araclon Biotech; BioClinica, Inc.; Biogen; Bristol-Myers Squibb Company; CereSpir, Inc.; Cogstate; Eisai Inc.; Elan Pharmaceuticals, Inc.; Eli Lilly and Company; EuroImmun; F. Hoffmann-La Roche Ltd and its affiliated company Genentech, Inc.; Fujirebio; GE Healthcare; IXICO Ltd.; Janssen Alzheimer Immunotherapy Research \& Development, LLC.; Johnson \& Johnson Pharmaceutical Research \& Development LLC.; Lumosity; Lundbeck; Merck \& Co., Inc.; Meso Scale Diagnostics, LLC.; NeuroRx Research; Neurotrack Technologies; Novartis Pharmaceuticals Corporation; Pfizer Inc.; Piramal Imaging; Servier; Takeda Pharmaceutical Company; and Transition Therapeutics. The Canadian Institutes of Health Research is providing funds to support ADNI clinical sites in Canada. Private sector contributions are facilitated by the Foundation for the National Institutes of Health (http://www.fnih.org). The grantee organization is the Northern California Institute for Research and Education, and the study is coordinated by the Alzheimer's Therapeutic Research Institute at the University of Southern California. ADNI data are disseminated by the Laboratory for Neuro Imaging at the University of Southern California.

\section{Compliance with ethical standards}

Conflicts of interest The authors of this manuscript have no conflicts of interests to disclose relevant to the current review.

Open Access This article is distributed under the terms of the Creative Commons Attribution 4.0 International License (http://creativeco mmons.org/licenses/by/4.0/), which permits unrestricted use, distribution, and reproduction in any medium, provided you give appropriate 
credit to the original author(s) and the source, provide a link to the Creative Commons license, and indicate if changes were made.

\section{References}

1. Harrington CR (2012) The molecular pathology of Alzheimer's disease. Neuroimaging Clin N Am 22:11-22 (vii)

2. McKhann GM, Knopman DS, Chertkow H, Hyman BT, Jack CR, Kawas CH, Klunk WE, Koroshetz WJ, Manly JJ, Mayeux R (2011) The diagnosis of dementia due to Alzheimer's disease: recommendations from the National Institute on Aging-Alzheimer's Association workgroups on diagnostic guidelines for Alzheimer's disease. Alzheimer's Dement 7:263-269

3. Albert MS, DeKosky ST, Dickson D, Dubois B, Feldman HH, Fox NC, Gamst A, Holtzman DM, Jagust WJ, Petersen RC (2011) The diagnosis of mild cognitive impairment due to Alzheimer's disease: recommendations from the National Institute on AgingAlzheimer's Association workgroups on diagnostic guidelines for Alzheimer's disease. Alzheimer's Dement 7:270-279

4. Politis M, Piccini P (2012) Positron emission tomography imaging in neurological disorders. J Neurol 259:1769-1780

5. Braak H, Braak E (1991) Neuropathological stageing of Alzheimer-related changes. Acta Neuropathol 82:239-259

6. Du A, Schuff N, Kramer J, Ganzer S, Zhu X, Jagust W, Miller B, Reed B, Mungas D, Yaffe K (2004) Higher atrophy rate of entorhinal cortex than hippocampus in AD. Neurology 62:422-427

7. Pennanen C, Kivipelto M, Tuomainen S, Hartikainen P, Hanninen T, Laakso MP, Hallikainen M, Vanhanen M, Nissinen A, Helkala EL, Vainio P, Vanninen R, Partanen K, Soininen H (2004) Hippocampus and entorhinal cortex in mild cognitive impairment and early AD. Neurobiol Aging 25:303-310

8. Oosterman JM, Oosterveld S, Rikkert MGO, Claassen JA, Kessels RP (2012) Medial temporal lobe atrophy relates to executive dysfunction in Alzheimer's disease. Int Psychogeriatr 24:1474-1482

9. Li X, Coyle D, Maguire L, Watson DR, McGinnity TM (2011) Gray matter concentration and effective connectivity changes in Alzheimer's disease: a longitudinal structural MRI study. Neuroradiology 53:733-748

10. Nesteruk M, Nesteruk T, Styczyńska M, Barczak A, Mandecka M, Walecki J, Barcikowska-Kotowicz M (2015) Predicting the conversion of mild cognitive impairment to Alzheimer's disease based on the volumetric measurements of the selected brain structures in magnetic resonance imaging. Neurol Neurochir Pol 49:349-353

11. Delli Pizzi S, Franciotti R, Bubbico G, Thomas A, Onofrj M, Bonanni L (2016) Atrophy of hippocampal subfields and adjacent extrahippocampal structures in dementia with Lewy bodies and Alzheimer's disease. Neurobiol Aging 40:103-109

12. Tam CW, Burton EJ, McKeith IG, Burn DJ, O’Brien JT (2005) Temporal lobe atrophy on MRI in Parkinson disease with dementia: a comparison with Alzheimer disease and dementia with Lewy bodies. Neurology 64:861-865

13. Cavedo E, Boccardi M, Ganzola R, Canu E, Beltramello A, Caltagirone C, Thompson P, Frisoni G (2011) Local amygdala structural differences with $3 \mathrm{~T}$ MRI in patients with Alzheimer disease. Neurology 76:727-733

14. Thomann PA, Dos Santos V, Toro P, Schönknecht P, Essig M, Schröder J (2009) Reduced olfactory bulb and tract volume in early Alzheimer's disease-a MRI study. Neurobiol Aging 30:838-841

15. Guo X, Wang Z, Li K, Li Z, Qi Z, Jin Z, Yao L, Chen K (2010) Voxel-based assessment of gray and white matter volumes in Alzheimer's disease. Neurosci Lett 468:146-150
16. De Jong L, Van der Hiele K, Veer I, Houwing J, Westendorp R, Bollen E, De Bruin P, Middelkoop H, Van Buchem M, Van Der Grond J (2008) Strongly reduced volumes of putamen and thalamus in Alzheimer's disease: an MRI study. Brain 131:3277-3285

17. Tagawa R, Hashimoto H, Matsuda Y, Uchida K, Yoshida A, Higashiyama S, Kawabe J, Toshihiro K, Shiomi S, Mori H (2014) Correlation between right medial temporal lobe atrophy and persecutory delusions in patients with dementia of the Alzheimer's type demonstrated on VSRAD advance. Osaka City Med J 60:73-80

18. Poulin SP, Dautoff R, Morris JC, Barrett LF, Dickerson BC (2011) Amygdala atrophy is prominent in early Alzheimer's disease and relates to symptom severity. Psychiatry Res Neuroimaging 194:7-13

19. Kilimann I, Grothe M, Heinsen H, Alho EJL, Grinberg L, Amaro E Jr, Dos Santos GAB, Da Silva RE, Mitchell AJ, Frisoni GB (2014) Subregional basal forebrain atrophy in Alzheimer's disease: a multicenter study. J Alzheimers Dis 40:687-700

20. Duarte A, Hayasaka S, Du A, Schuff N, Jahng G-H, Kramer J, Miller B, Weiner M (2006) Volumetric correlates of memory and executive function in normal elderly, mild cognitive impairment and Alzheimer's disease. Neurosci Lett 406:60-65

21. Roy R, Niccolini F, Pagano G, Politis M (2016) Cholinergic imaging in dementia spectrum disorders. Eur J Nucl Med Mol Imaging 43:1376-1386

22. Vasavada MM, Wang J, Eslinger PJ, Gill DJ, Sun X, Karunanayaka P, Yang QX (2015) Olfactory cortex degeneration in Alzheimer's disease and mild cognitive impairment. J Alzheimers Dis 45:947-958

23. Tabatabaei-Jafari H, Walsh E, Shaw ME, Cherbuin N, Initiative AsDN (2017) The cerebellum shrinks faster than normal ageing in A lzheimer's disease but not in mild cognitive impairment. Hum Brain Mapp 38:3141-3150

24. Lee JH, Ryan J, Andreescu C, Aizenstein H, Lim HK (2015) Brainstem morphological changes in Alzheimer's disease. Neuroreport $26: 411$

25. Moonga I, Niccolini F, Wilson H, Pagano G, Politis M, Initiative AsDN (2017) Hypertension is associated with worse cognitive function and hippocampal hypometabolism in Alzheimer's disease. Eur J Neurol 24:1173-1182

26. Fazekas F, Kleinert R, Offenbacher H, Schmidt R, Kleinert G, Payer F, Radner H, Lechner H (1993) Pathologic correlates of incidental MRI white matter signal hyperintensities. Neurology 43:1683-1683

27. Capizzano AA, Acion L, Bekinschtein T, Furman M, Gomila H, Martinez A, Mizrahi R, Starkstein S (2004) White matter hyperintensities are significantly associated with cortical atrophy in Alzheimer's disease. J Neurol Neurosurg Psychiatry 75:822-827

28. de Leeuw FE, Barkhof F, Scheltens P (2004) White matter lesions and hippocampal atrophy in Alzheimer's disease. Neurology 62:310-312

29. Debette S, Bombois S, Bruandet A, Delbeuck X, Lepoittevin S, Delmaire C, Leys D, Pasquier F (2007) Subcortical hyperintensities are associated with cognitive decline in patients with mild cognitive impairment. Stroke 38:2924-2930

30. Berlow YA, Wells WM, Ellison JM, Sung YH, Renshaw PF, Harper DG (2010) Neuropsychiatric correlates of white matter hyperintensities in Alzheimer's disease. Int J Geriatr Psychiatry 25:780-788

31. Altamura C, Scrascia F, Quattrocchi CC, Errante Y, Gangemi E, Curcio G, Ursini F, Silvestrini M, Maggio P, Beomonte Zobel B (2016) Regional MRI diffusion, white-matter hyperintensities, and cognitive function in Alzheimer's disease and vascular dementia. J Clin Neurol 12:201-208

32. van Straaten EC, Harvey D, Scheltens P, Barkhof F, Petersen RC, Thal LJ, Jack CR, DeCarli C (2008) Periventricular white 
matter hyperintensities increase the likelihood of progression from amnestic mild cognitive impairment to dementia. J Neurol 255:1302

33. Madden DJ, Bennett IJ, Burzynska A, Potter GG, Chen N-k, Song AW (2012) Diffusion tensor imaging of cerebral white matter integrity in cognitive aging. Biochim Biophys Acta Mol Basis Dis 1822:386-400

34. Sexton CE, Kalu UG, Filippini N, Mackay CE, Ebmeier KP (2011) A meta-analysis of diffusion tensor imaging in mild cognitive impairment and Alzheimer's disease. Neurobiol Aging 32:2322 (e2325-2322. e2318)

35. Brüggen K, Dyrba M, Barkhof F, Hausner L, Filippi M, Nestor PJ, Hauenstein K, Klöppel S, Grothe MJ, Kasper E (2015) Basal forebrain and hippocampus as predictors of conversion to Alzheimer's disease in patients with mild cognitive impairment - a multicenter DTI and volumetry study. J Alzheimers Dis 48:197-204

36. Sjöbeck M, Elfgren C, Larsson E-M, Brockstedt S, Lätt J, Englund E, Passant U (2010) Alzheimer's disease (AD) and executive dysfunction. A case-control study on the significance of frontal white matter changes detected by diffusion tensor imaging (DTI). Arch Gerontol Geriatr 50:260-266

37. Hirni DI, Kivisaari SL, Monsch AU, Taylor KI (2013) Distinct neuroanatomical bases of episodic and semantic memory performance in Alzheimer's disease. Neuropsychologia 51:930-937

38. Zhang Y, Schuff N, Du A-T, Rosen HJ, Kramer JH, Gorno-Tempini ML, Miller BL, Weiner MW (2009) White matter damage in frontotemporal dementia and Alzheimer's disease measured by diffusion MRI. Brain 132:2579-2592

39. Firbank MJ, Watson R, Mak E, Aribisala B, Barber R, Colloby SJ, He J, Blamire AM, O’Brien JT (2016) Longitudinal diffusion tensor imaging in dementia with Lewy bodies and Alzheimer's disease. Parkinsonism Relat Disord 24:76-80

40. Mori S, Zhang J (2006) Principles of diffusion tensor imaging and its applications to basic neuroscience research. Neuron 51:527-539

41. Alexopoulos P, Sorg C, Förschler A, Grimmer T, Skokou M, Wohlschläger A, Perneczky R, Zimmer C, Kurz A, Preibisch C (2012) Perfusion abnormalities in mild cognitive impairment and mild dementia in Alzheimer's disease measured by pulsed arterial spin labeling MRI. Eur Arch Psychiatry Clin Neurosci 262:69-77

42. Mak HK-F, Qian W, Ng KS, Chan Q, Song Y-Q, Chu LW, Yau KK-W (2014) Combination of MRI hippocampal volumetry and arterial spin labeling MR perfusion at 3-Tesla improves the efficacy in discriminating Alzheimer's disease from cognitively normal elderly adults. J Alzheimers Dis 41:749-758

43. Dai W, Lopez OL, Carmichael OT, Becker JT, Kuller LH, Gach HM (2009) Mild cognitive impairment and alzheimer disease: patterns of altered cerebral blood flow at MR imaging. Radiology 250:856-866

44. Chao LL, Buckley ST, Kornak J, Schuff N, Madison C, Yaffe K, Miller BL, Kramer JH, Weiner MW (2010) ASL perfusion MRI predicts cognitive decline and conversion from MCI to dementia. Alzheimer Dis Assoc Disord 24:19

45. Gao Y-Z, Zhang J-J, Liu H, Wu G-Y, Xiong L, Shu M (2013) Regional cerebral blood flow and cerebrovascular reactivity in Alzheimer's disease and vascular dementia assessed by arterial spinlabeling magnetic resonance imaging. Curr Neurovasc Res 10:49-53

46. Binnewijzend MA, Kuijer JP, van der Flier WM, Benedictus MR, Möller CM, Pijnenburg YA, Lemstra AW, Prins ND, Wattjes MP, van Berckel BN (2014) Distinct perfusion patterns in Alzheimer's disease, frontotemporal dementia and dementia with Lewy bodies. Eur Radiol 24:2326-2333

47. Alsaedi A, Thomas D, Bisdas S, Golay X (2018) Overview and critical appraisal of arterial spin labelling technique in brain perfusion imaging. Contrast Media Mol Imaging. https://doi. org/10.1155/2018/5360375

48. Reiman EM, Jagust WJ (2012) Brain imaging in the study of Alzheimer's disease. Neuroimage 61:505-516

49. Zhu X, Schuff N, Kornak J, Soher B, Yaffe K, Kramer JH, Ezekiel F, Miller BL, Jagust WJ, Weiner MW (2006) Effects of Alzheimer disease on fronto-parietal brain $\mathrm{N}$-acetyl aspartate and myo-inositol using magnetic resonance spectroscopic imaging. Alzheimer Dis Assoc Disord 20:77

50. Tumati S, Martens S, Aleman A (2013) Magnetic resonance spectroscopy in mild cognitive impairment: systematic review and meta-analysis. Neurosci Biobehav Rev 37:2571-2586

51. Kantarci K (2013) Proton MRS in mild cognitive impairment. J Magn Reson Imaging 37:770-777

52. Falini A, Bozzali M, Magnani G, Pero G, Gambini A, Benedetti B, Mossini R, Franceschi M, Comi G, Scotti G (2005) A whole brain MR spectroscopy study from patients with Alzheimer's disease and mild cognitive impairment. Neuroimage 26:1159-1163

53. Weiss U, Bacher R, Vonbank H, Kemmler G, Lingg A, Marksteiner J (2003) Cognitive impairment: assessment with brain magnetic resonance imaging and proton magnetic resonance spectroscopy. J Clin Psychiatry 64:235-242

54. Su L, Blamire A, Watson R, He J, Hayes L, O'brien J (2016) Whole-brain patterns of $1 \mathrm{H}$-magnetic resonance spectroscopy imaging in Alzheimer's disease and dementia with Lewy bodies. Transl Psychiatry 6:e877

55. Chatham JC, Blackband SJ (2001) Nuclear magnetic resonance spectroscopy and imaging in animal research. IlAR J 42:189-208

56. Logothetis NK, Pauls J, Augath M, Trinath T, Oeltermann A (2001) Neurophysiological investigation of the basis of the fMRI signal. Nature 412:150

57. Small SA, Perera GM, DeLaPaz R, Mayeux R, Stern Y (1999) Differential regional dysfunction of the hippocampal formation among elderly with memory decline and Alzheimer's disease. Ann Neurol 45:466-472

58. Sperling RA, Bates J, Chua E, Cocchiarella A, Rentz D, Rosen B, Schacter D, Albert M (2003) fMRI studies of associative encoding in young and elderly controls and mild Alzheimer's disease. J Neurol Neurosurg Psychiatry 74:44-50

59. Petrella JR, Wang L, Krishnan S, Slavin MJ, Prince SE, Tran T-TT, Doraiswamy PM (2007) Cortical deactivation in mild cognitive impairment: high-field-strength functional MR imaging. Radiology 245:224-235

60. Trivedi MA, Murphy CM, Goetz C, Shah RC, Gabrieli JD, Whitfield-Gabrieli S, Turner DA, Stebbins GT (2008) fMRI activation changes during successful episodic memory encoding and recognition in amnestic mild cognitive impairment relative to cognitively healthy older adults. Dement Geriatr Cogn Disord 26:123-137

61. Parra MA, Pattan V, Wong D, Beaglehole A, Lonie J, Wan HI, Honey G, Hall J, Whalley HC, Lawrie SM (2013) Medial temporal lobe function during emotional memory in early Alzheimer's disease, mild cognitive impairment and healthy ageing: an fMRI study. BMC Psychiatry 13:76

62. Yetkin FZ, Rosenberg RN, Weiner MF, Purdy PD, Cullum CM (2006) FMRI of working memory in patients with mild cognitive impairment and probable Alzheimer's disease. Eur Radiol 16:193-206

63. Thiyagesh SN, Farrow TF, Parks RW, Accosta-Mesa H, Young C, Wilkinson ID, Hunter MD, Woodruff PW (2009) The neural basis of visuospatial perception in Alzheimer's disease and healthy elderly comparison subjects: an fMRI study. Psychiatry Res Neuroimaging 172:109-116 
64. Li C, Zheng J, Wang J, Gui L, Li C (2009) An fMRI stroop task study of prefrontal cortical function in normal aging, mild cognitive impairment, and Alzheimer's disease. Curr Alzheimer Res 6:525-530

65. McGeown WJ, Shanks MF, Forbes-McKay KE, Venneri A (2009) Patterns of brain activity during a semantic task differentiate normal aging from early Alzheimer's disease. Psychiatry Res Neuroimaging 173:218-227

66. Vidoni ED, Thomas GP, Honea RA, Loskutova N, Burns JM (2012) Evidence of altered corticomotor system connectivity in early-stage Alzheimer's disease. J Neurol Phys Ther 36:8

67. Van Dam NT, Sano M, Mitsis EM, Grossman HT, Gu X, Park Y, Hof PR, Fan J (2013) Functional neural correlates of attentional deficits in amnestic mild cognitive impairment. PLoS One 8:e54035

68. Greicius MD, Krasnow B, Reiss AL, Menon V (2003) Functional connectivity in the resting brain: a network analysis of the default mode hypothesis. Proc Natl Acad Sci 100:253-258

69. Greicius MD, Srivastava G, Reiss AL, Menon V (2004) Defaultmode network activity distinguishes Alzheimer's disease from healthy aging: evidence from functional MRI. Proc Natl Acad Sci USA 101:4637-4642

70. Celebi O, Uzdogan A, Oguz KK, Has AC, Dolgun A, Cakmakli GY, Akbiyik F, Elibol B, Saka E (2016) Default mode network connectivity is linked to cognitive functioning and CSF A $\beta 1-42$ levels in Alzheimer's disease. Arch Gerontol Geriatr 62:125-132
71. Damoiseaux JS, Prater KE, Miller BL, Greicius MD (2012) Functional connectivity tracks clinical deterioration in Alzheimer's disease. Neurobiol Aging 33:828 (e819-828. e830)

72. Yu E, Liao Z, Mao D, Zhang Q, Ji G, Li Y, Ding Z (2017) Directed functional connectivity of posterior cingulate cortex and whole brain in Alzheimer's disease and mild cognitive impairment. Curr Alzheimer Res 14:628-635

73. Das SR, Pluta J, Mancuso L, Kliot D, Orozco S, Dickerson BC, Yushkevich PA, Wolk DA (2013) Increased functional connectivity within medial temporal lobe in mild cognitive impairment. Hippocampus 23:1-6

74. Zhou B, Liu Y, Zhang Z, An N, Yao H, Wang P, Wang L, Zhang $X$, Jiang $T$ (2013) Impaired functional connectivity of the thalamus in Alzheimer's disease and mild cognitive impairment: a resting-state fMRI study. Curr Alzheimer Res 10:754-766

75. Li R, Wu X, Fleisher AS, Reiman EM, Chen K, Yao L (2012) Attention-related networks in Alzheimer's disease: a resting functional MRI study. Hum Brain Mapp 33:1076-1088

76. Zheng W, Liu X, Song H, Li K, Wang Z (2017) Altered functional connectivity of cognitive-related cerebellar subregions in Alzheimer's disease. Front Aging Neurosci 9:143

77. Rocchi L, Niccolini F, Politis M (2015) Recent imaging advances in neurology. J Neurol 262:2182-2194

78. Bandettini PA (2009) Functional MRI limitations and aspirations. In: Neural correlates of thinking. Springer, New York, pp 15-38 